\title{
Experimental Investigation of Temperature Effects on Low Salinity Enzyme Enhanced Oil Recovery Process
}

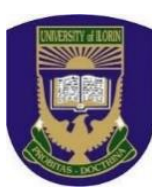

\author{
Tinuola H. Udoh*
}

Department of Chemical/Petrochemical Engineering, Akwa Ibom State University, Ikot Akpaden, Nigeria.

ABSTRACT: In this paper, the effect of temperature on low salinity brine and combined low salinity enzyme oil recovery processes in sandstone rock sample was experimentally investigated. The core flooding displacement tests were conducted with the injection of the enzyme in post-tertiary mode after secondary high salinity brine and tertiary low salinity brine injection processes. Effluents analyses of each of the flooding were carried out and used to evaluate the effect of temperature on rock-fluid interactions and enhanced oil recovery processes. The results showed that tertiary low salinity brine injection and post-tertiary enzyme injection increased recovery by $2.4-8.72 \%$ over the secondary high salinity brine flooding at $25{ }^{\circ} \mathrm{C}$. Also, increase in oil recovery $(0.57-13.18 \%)$ was observed with increase in the system temperature from $25^{\circ} \mathrm{C}$ to $70{ }^{\circ} \mathrm{C}$. Furthermore, the effluent of the $70{ }^{\circ} \mathrm{C}$ flooding was associated with the earliest low salinity brine ionic breakthrough front at 10 injected pore volume, while the $25{ }^{\circ} \mathrm{C}$ flooding breakthrough front occurred at 22 pore volume. However, no obvious effect of temperature on $\mathrm{pH}$ of the effluents was observed with all the floodings, but temperature effects were observed with the conductivity and ionic concentrations of all the effluents as evident by varied breakthrough times. Hence, the observed increased recovery in this study is attributable to combined effects of electric double-layer expansion, oil viscosity reduction and interfacial tension reduction. This novel study of the combined low salinity enzyme injection process is significant for the design of enzyme enhanced oil recovery processes.

KEYWORDS: Enhanced oil recovery, enzyme, sandstone, low salinity, core flooding, temperature.

[Received April 1, 2020, Revised August 9, 2020, Accepted August 22, 2020]

Print ISSN: 0189-9546 | Online ISSN: 2437-2110

\section{INTRODUCTION}

Crude oil production sequence from reservoirs located in subsurface under high pressure and temperature is generally classified as primary, secondary and tertiary recovery processes (Al-Adasani and Bai, 2010). The aftermath effect of poor displacement efficiency of primary oil recovery by pressure depletion and secondary oil recovery by water flooding is oil trapping. This makes about two-third of oil initially in place to be unproductive due to combined effects of microscopic and macroscopic factors (Levitt, 2006). The microscopic factors such as oil-water interfacial tension (IFT), capillary force and wettability that trap oil in smaller pores result in residual oil saturation in the swept region after displacement process. The macroscopic factors such as permeability heterogeneity, viscous fingering and negative capillary force at oil-water interface result in remaining oil saturation in the unswept region. Oil production enhancement processes will therefore require alteration of these forces acting on the system through the use of appropriate enhanced oil recovery (EOR) techniques (Al-Adasani and Bai, 2010).

Recent studies have shown that the microscopic displacement can be enhanced by wettability modification with cheap low salinity brine flooding processes. However, different mechanisms have been proposed for the effective low salinity brine (LSB) flooding such as wettability alteration, clay swelling and fine migration, increased $\mathrm{pH}$ and interfacial tension reduction, multi-component ion exchange (MIE),

*Corresponding author: tinuolaudoh@aksu.edu.ng double-layer expansion, salting-in effect and formation of micro-dispersions micelles (Tang and Morrow, 1997; Sharma and Filoco, 2000; McGuire et al., 2005; Lager et al., 2006; Pu et al., 2008; Ligthelm, et al., 2009; RezaeiDoust et al., 2009; Austad et al., 2010; Alagic and Skauge, 2010; Hughes et al., 2010; Sheng, 2014; Sohrabi , et al., 2015). Despite the number of previous studies on LSB EOR potential, the underlying mechanism(s) is still debatable and its positive effect is not always observed in all flooding although additional recovery as high as $25 \%$ oil initially in place (OIIP) has been reported in the past (Morrow and Buckley, 2011).

Other studies have also explored the possibility of increasing oil production with the use of combined low salinity brine and chemical surfactant flooding and they found the combined process to be more efficient than applying either of them alone (Alagic and Skauge, 2010; Johannessen and Spildo, 2013; Johannessen and Spildo, 2014). The cumulative effect of continuous chemical surfactants usage however constitutes an environmental threat due to their toxicity and non-degradable nature (Van Hamme et al., 2006). Therefore, biologically generated surface-active compounds are being considered as possible alternatives to chemical surfactants. Udoh and Vinogradov (2019a) carried out extensive experimental studies on the behaviour of two biologically generated surface-active gents (rhamnolipid and greenzyme) in brines relevant to hydrocarbon reservoirs and their results showed that they both exhibited good stability at high 
temperature and in multi-component brine solutions. However, rhamnolipid tends to be sensitive to brine composition and salinity.

Furthermore, enzyme enhanced oil recovery is an emerging EOR method with the capacity to improve water flooding, thereby reducing residual oil saturation in reservoir pores (Nasiri et al., 2009; Wang, 2010; Khusainova et al., 2013). Enzymes are organic catalysts that expedite reactions that will otherwise proceed slowly without them by enhancing intermolecular adsorption between substances. All known enzymes are proteins but all proteins are not enzymes (Kuznetsov, 2012).

Protein-enzymes are biological agents created from microbial technology by combining low molecular weight amphipathic protein with enzymes through enzymatic reaction with enhanced surface-active properties (Xia, 2001). Previous study by Nasiri et al. (2009) observed that greenzyme application altered sandstone rock surface wettability towards increased water-wetness. Similar wettability alteration trend was observed by Khusainova et al. (2013) with the application of enzymes on calcite system. Also, recent studies by Udoh et al. (2018) and Udoh and Vinogradov (2019b) demonstrated the enhanced oil recovery capacity of enzyme application in carbonate rocks in which increased oil recovery was observed in all modes of applications. Limited studies are however available on enzyme EOR in sandstone rocks and the potential of combining enzyme with low salinity brine has not been explored.

The objective of this work is therefore, to carry out experimental investigations on effect of temperature on EOR processes of LSB flooding and low salinity enzyme (LSEZ) flooding in sandstone rock sample in order to improve the understanding of the underlying mechanism(s). To achieve these objectives, comprehensive core flooding experiments were carried out at three different system temperatures. Effluents from each of the flooding were analysed and used to evaluate the effects of temperature on the dynamic rock-fluid interactions and enhanced oil recovery processes.

\section{MATERIALS AND METHODS}

\section{A. Brine and Crude Oil}

The compositional breakdown of the two brines used in this study are presented in Table 1. The brine used as formation brine (FMB) was synthetic seawater, while the low salinity brine (LSB) used was $10 \%$ seawater. The reagent grade of sodium chloride $(\mathrm{NaCl})$, calcium chloride dihydrate $\left(\mathrm{CaCl}_{2} .2 \mathrm{H}_{2} \mathrm{O}\right)$, magnesium chloride hexahydrate $\left(\mathrm{MgCl}_{2} \cdot 6 \mathrm{H}_{2} \mathrm{O}\right)$ and sodium sulphate $\left(\mathrm{Na}_{2} \mathrm{SO}_{4}\right)$ salts of $>95 \%$ purity were used to prepare the brines with deionised water. The crude oil used in this study is a dead medium crude oil from the North Sea in Europe and the properties of the crude oil measured at $25^{\circ} \mathrm{C}$ are presented in Table 2.
Table 1: Composition of the brine solutions used for the experiments.

\begin{tabular}{ccc}
\hline Ions & FMB (M) & LSB (M) \\
\hline $\mathrm{Na}^{+}$ & 0.550 & 0.0061 \\
$\mathrm{Ca}^{2+}$ & 0.014 & 0.0002 \\
$\mathrm{Mg}^{2+}$ & 0.045 & 0.0005 \\
$\mathrm{Cl}^{-}$ & 0.624 & 0.0069 \\
$\mathrm{SO}_{4}{ }^{2-}$ & 0.024 & 0.0003 \\
Ionic strength & 0.750 & 0.0083 \\
\hline
\end{tabular}

Table 2: Crude oil properties.

\begin{tabular}{lc}
\hline Oil properties & Quantity \\
\hline Density $(\mathrm{g} / \mathrm{cc})$ & 0.91 \\
Viscosity (cp) & 50.61 \\
API $\left({ }^{\circ}\right)$ & 24.34 \\
TAN $(\mathrm{mg} \mathrm{KOH} / \mathrm{g})$ & 3.91 \\
TBN $(\mathrm{mg} \mathrm{KOH} / \mathrm{g})$ & 1.40 \\
Asphaltene (wt.\%) & 0.85 \\
\hline
\end{tabular}

\section{B. Enzyme}

The enzyme used in this study is $100 \%$ greenzyme supplied by Biotech Processing Supply, Dallas Texas. Greenzyme is water soluble enzyme produced from DNA of selective oileating cultured microbes and it has been previously used to improve oil recovery in enzyme EOR process (Wang, et al., 2008; Nasiri et al., 2009; Khusainova et al., 2013). Greenzyme has good surface activity, high tolerance for brine of different compositions, salinities and high temperature systems (Udoh and Vinogradov, 2019a; Udoh and Vinogradov, 2019c).

\section{Core Plugs}

The core plugs used in this study were from an outcrop Clashach sandstone rock from Scotland. The main composition of these rock samples as determined by X-ray diffraction and scanning electron microscopy analyses are presented in Table 3. The basic properties of the three core plugs used for the displacement experiments are presented in Table 4.

Table 3: Sandstone compositional breakdown.

\begin{tabular}{lc}
\hline Components & Amount (wt.\%) \\
\hline $\mathrm{SiO}_{2}$ & 92 \\
$\mathrm{KAlSi}_{3} \mathrm{O}_{8}$ & 5 \\
$\mathrm{FeTiO}$ & $<0.5$ \\
$\mathrm{TiO}_{2}$ & $<0.5$ \\
$\mathrm{ZrO}_{2}$ & $<0.5$ \\
$\mathrm{Al}_{2} \mathrm{O}_{3}$ & $<0.5$ \\
$\mathrm{Others}$ & $<1$ \\
\hline
\end{tabular}

Table 4: Basic petrophysical properties of core plugs.

\begin{tabular}{lllll}
\hline Plug ID & L $(\mathbf{c m})$ & D $(\mathbf{c m})$ & $\boldsymbol{\phi}$ & K $(\mathbf{m D})$ \\
\hline S01 & 7.72 & 3.68 & 0.12 & 118.67 \\
S02 & 7.70 & 3.66 & 0.14 & 119.83 \\
S03 & 7.84 & 3.69 & 0.13 & 119.84 \\
\hline
\end{tabular}

\section{Core Preparation}

Before the core flooding process, the core plugs were thoroughly cleaned in a Soxhlet extractor unit with methanol for 24 hours to remove all the impurities. The cores were thereafter dried in the oven at $80{ }^{\circ} \mathrm{C}$ for 48 hours, cooled and dimensional measurements were carried out on each plug. Thereafter, core plugs were saturated with formation brine under vacuum and then drained with crude oil using a constant injection flow rate of $1 \mathrm{ml} / \mathrm{min}$ till no water was produced. 
Finally, the core plugs were subjected to ageing process in the oven at $75^{\circ} \mathrm{C}$ for six weeks in order to alter their wetting states.

\section{E. Core flooding design and procedure}

Three sequences (secondary, tertiary and post-tertiary) of flooding were used to investigate the EOR potential of low salinity brine (LSB) and low salinity enzyme (LSEZ) brine injection in this study. The secondary mode flooding was defined by direct injection of FMB brine and the end of secondary flooding was defined by injection of a minimum of 5 pore volume (PV) of FMB into the cores in order to ensure complete displacement of all mobile oil before the commencement of the tertiary injection. The tertiary mode flooding involves the injection of LSB after the secondary flooding while post-tertiary flooding involves additional injection of the LSEZ brine after tertiary mode.

Three sets of core flooding experiments were carried out at three different temperatures $\left(25^{\circ} \mathrm{C}, 50^{\circ} \mathrm{C}\right.$ and $\left.70{ }^{\circ} \mathrm{C}\right)$. All the core plugs were subjected to similar flooding procedures in which the brines were used to displace the oil from the bottom of the plugs at a constant injection rate of $1 \mathrm{ml} / \mathrm{min}$ until no oil production was observed. Thereafter, the injection rate was changed to $3 \mathrm{ml} / \mathrm{min}$ to ensure the displacement of all the mobile oil before the commencement of the tertiary EOR process. The LSEZ brine composition was formulated by adding $1 \mathrm{wt} . \%$ greenzyme concentration to LSB solution. This concentration was used based on the previous study on interfacial tests that showed its effective potential (Udoh and Vinogradov, 2019a).

The $\mathrm{pH}$, specific conductivity measurements and the divalent cations $\left(\mathrm{Ca}^{2+}\right.$ and $\left.\mathrm{Mg}^{2+}\right)$ concentrations of all the effluents from each flooding process were analyzed. The Thermo Scientific $\mathrm{pH}$ meter was used for the $\mathrm{pH}$ measurements while the Mettler Toledo conductivity meter was used for the specific conductivity measurements and the microwave plasma atomic emission spectroscopy (MP-AES) was used for the ion concentrations analysis. The $\mathrm{pH}$ of the effluents was measured because increase in $\mathrm{pH}$ is one of the mechanisms attributed to the effective LSB flooding and $\mathrm{pH}$ measurement can also indicate of the effects of rock-fluid interactions which can improve the understanding of the process.

Also, the ion analysis was used to monitor the activity of the divalent cations in the system during flooding, while the specific conductivity measurement was used to monitor the overall ionic activity during the flooding process. These were done because ionic activity is fundamental to some proposed mechanisms for effective LSB flooding such as multi-ion exchange and electric double layer expansion.

\section{RESULTS AND DISCUSSION}

\section{A. Presentation of Results}

Figure 1 shows the results of the first flooding experiment carried out at $25{ }^{\circ} \mathrm{C}$. The total recovery of $65.94 \%$ OIIP was made with an injection of about 6.34 PV with no further oil production being observed. However, the implementation of LSB in tertiary mode increased recovery to $74.66 \%$ OIIP with injection of additional $11 \mathrm{PV}$ brine. This is equivalent to $8.72 \%$ OIIP additional oil recovery over the high salinity FMB flooding. Further flooding with LSEZ brine in post-tertiary mode resulted in an incremental recovery of $5.34 \%$ OIIP and total recovery of $80.00 \%$ OIIP. This shows the viability of LSB flooding and LSEZ brine flooding at residual oil saturation.

The results of the $\mathrm{pH}$ and conductivity measurements of the effluents of this flooding are presented in Figure 1(b). A slight increase in $\mathrm{pH}$ was observed during LSB and LSEZ brine flooding in comparison to the high salinity FMB flooding. From the result of the conductivity measurements, an initial steady high conductivity values that signifies high ionic activity was observed during FMB secondary flooding, but this later reduced to steady low values during LSB and LSEZ floodings. The LSB breakthrough front that shows the transition from high ionic activity to low ionic activity was observed at around 22 injected pore volume (PV).

Also from the results of the divalent cations analysis shown in Figure 1c, a similar trend to the conductivity measurement was observed with ionic concentration profiles. During high salinity FMB secondary flooding, the concentrations of $\mathrm{Ca}^{2+}$ and $\mathrm{Mg}^{2+}$ in the effluents were approximately equal to the injected concentrations. Flooding with this high salinity brine was associated with high ionic activity (RezaeiDoust et al., 2009) as evident by high conductivity values of the effluents of this phase of flooding. However, during the tertiary implementation with the LSB injection, the concentrations of $\mathrm{Ca}^{2+}$ and $\mathrm{Mg}^{2+}$ both reduced but they were slightly higher than the injected concentrations and LSEZ flooding further increased these concentrations. This suggests the possibility of desorption of these ions during LSB and LSEZ floodings.

Furthermore, the breakthroughs of these ionic concentrations in the LSB were also observed at about $22 \mathrm{PV}$ as evidenced by the ionic activity changes in the conductivity of the effluents. The observed initial high conductivity and ionic concentrations during LSB flooding can be attributed to the effect of connate water saturation and residue of secondary FMB flooding in the core. This is evidenced by the reduction of the respective ionic concentration toward the injected concentrations during LSB flooding. However, the observed slight increase in the ionic concentrations during LSB and further increase during LSEZ floodings suggests the possibility of desorption of $\mathrm{Ca}^{2+}$ and $\mathrm{Mg}^{2+}$ ions during flooding. This can be related to enzyme adsorption on sandstone rock surface as detailed in the previous studies by Udoh (2019) and Udoh and Ekanem, (2020). Further discussions on this result are presented in the later section. 


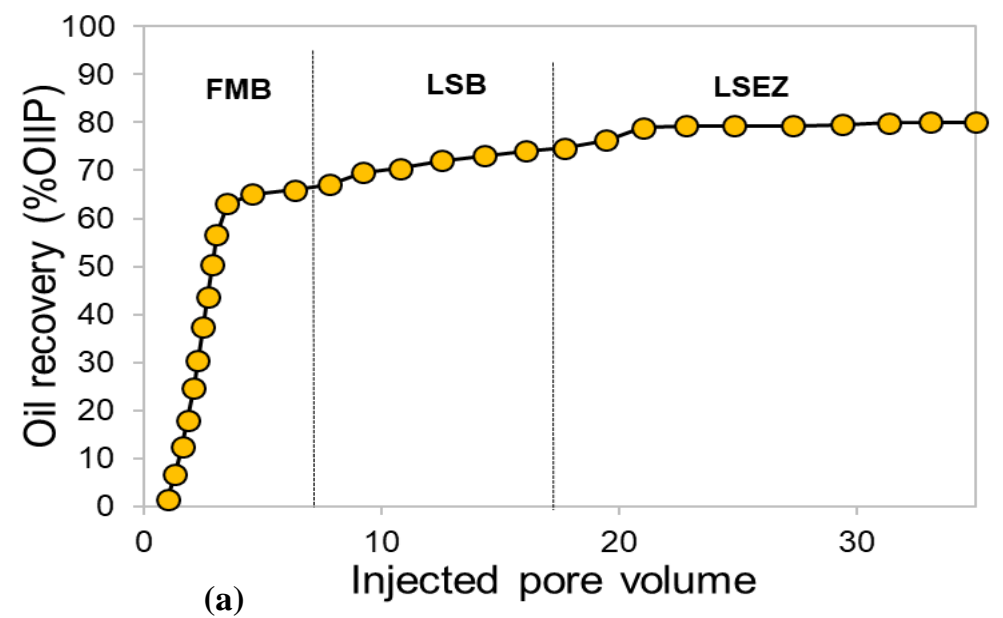

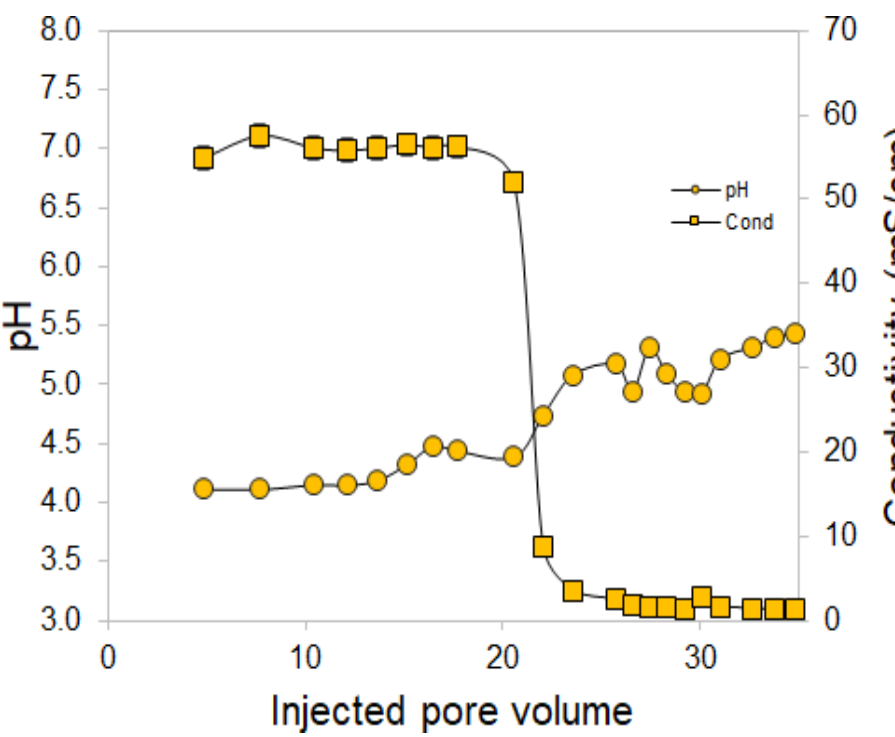

(b)

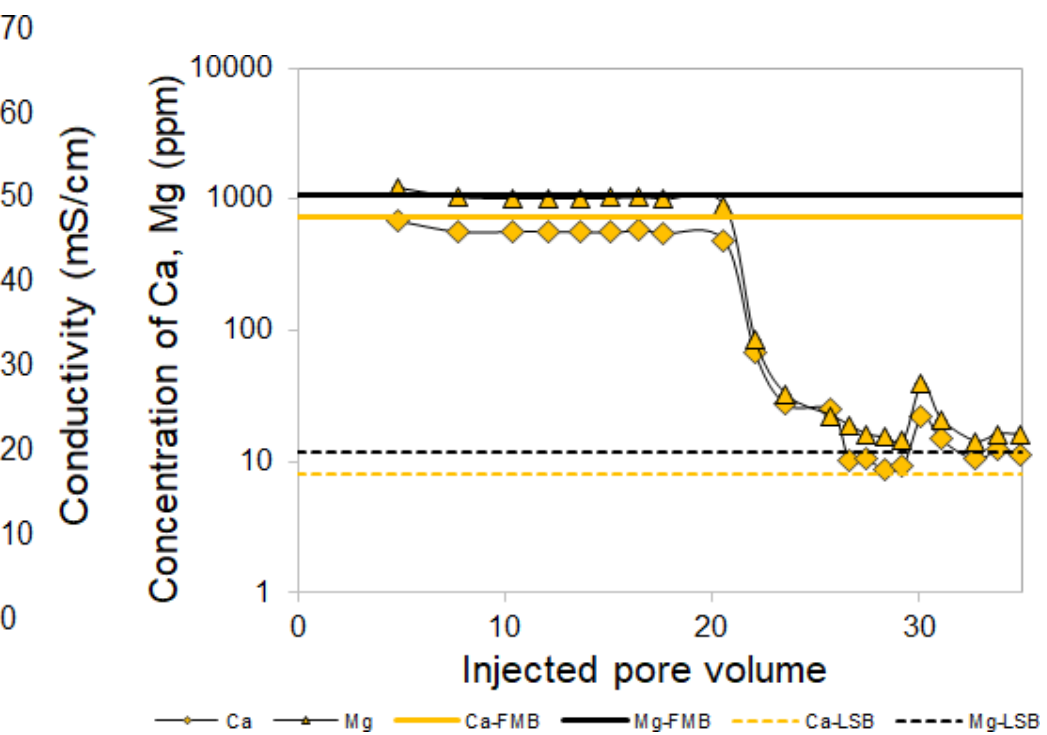

(c)

Figure 1: Flooding on core $\mathrm{S} 01$ at $25{ }^{\circ} \mathrm{C}$, (a) oil recovery (b) effluents' $\mathrm{pH}$ and conductivity (c) concentrations of $\mathrm{Ca}^{2+}$ and $\mathrm{Mg}^{2+}$ ions in effluents. The straight and dashed lines indicate $\mathrm{Ca}^{2+}$ (coloured) and $\mathrm{Mg}^{2+}$ (black) concentrations in connate water and injected brines respectively.

The results of the second flooding carried out at $50{ }^{\circ} \mathrm{C}$ are presented in Figure 2. The secondary high salinity FMB flooding resulted in $78.55 \%$ OIIP recovery with continuous injection of $6.64 \mathrm{PV}$ brine until no recovery was observed. The tertiary implementation of LSB flooding however resulted in an additional recovery of $4.34 \%$ OIIP and the post-tertiary LSEZ flooding increased the total recovery to $85.34 \%$ OIIP, which is equivalent to $2.45 \%$ incremental recovery. The result of the $\mathrm{pH}$ measurements of the effluents from this flooding (Figure $2 b$ ) shows a slight progressive increase in $\mathrm{pH}$ with the change of injection fluid from FMB to LSB and then to LSEZ brine. The conductivity analysis of these effluents showed a similar trend to the previous flooding at $25{ }^{\circ} \mathrm{C}$ in which initial high conductivity that later reduced with further flooding was observed. Also, the results of the ionic concentrations analysis of the effluents (Figure 2c) showed a similar trend to the first flooding with initial high concentrations of $\mathrm{Ca}^{2+}$ and $\mathrm{Mg}^{2+}$ that later reduced with further flooding. The LSB breakthrough front of this flooding was however observed at around 14 injected PV, which is earlier than the previous low-temperature flooding. Also, the $\mathrm{Ca}^{2+}$ and $\mathrm{Mg}^{2+}$ concentrations did not reduce to their respective injected concentrations during LSB and LSEZ floodings. This further confirms the possibility of desorption of these ions during these flooding phases as opposed the high salinity flooding. 


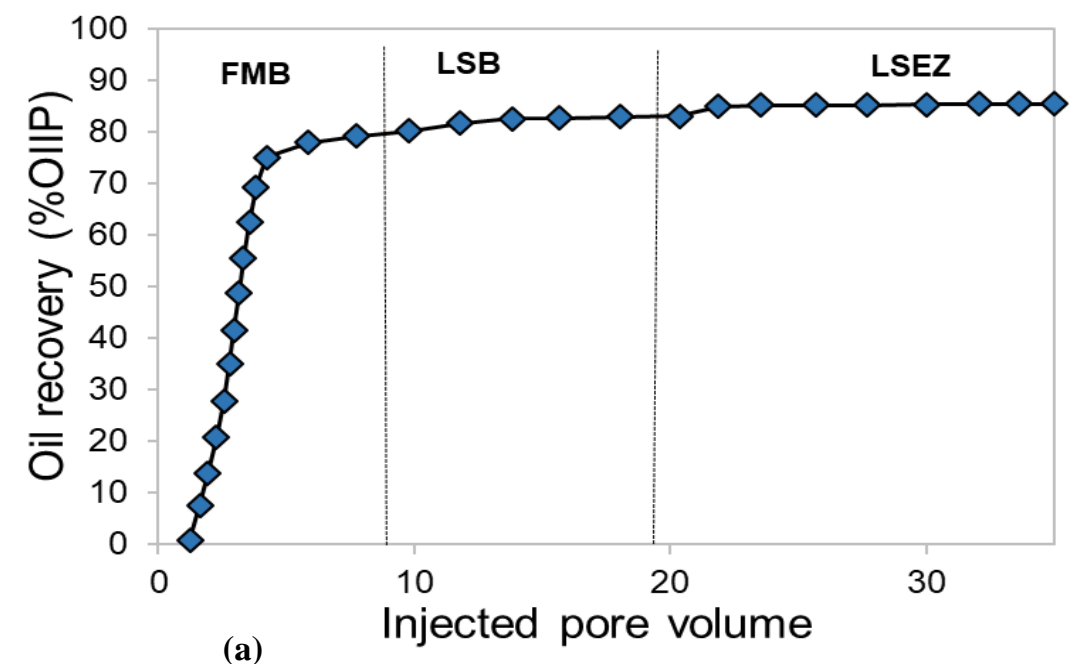

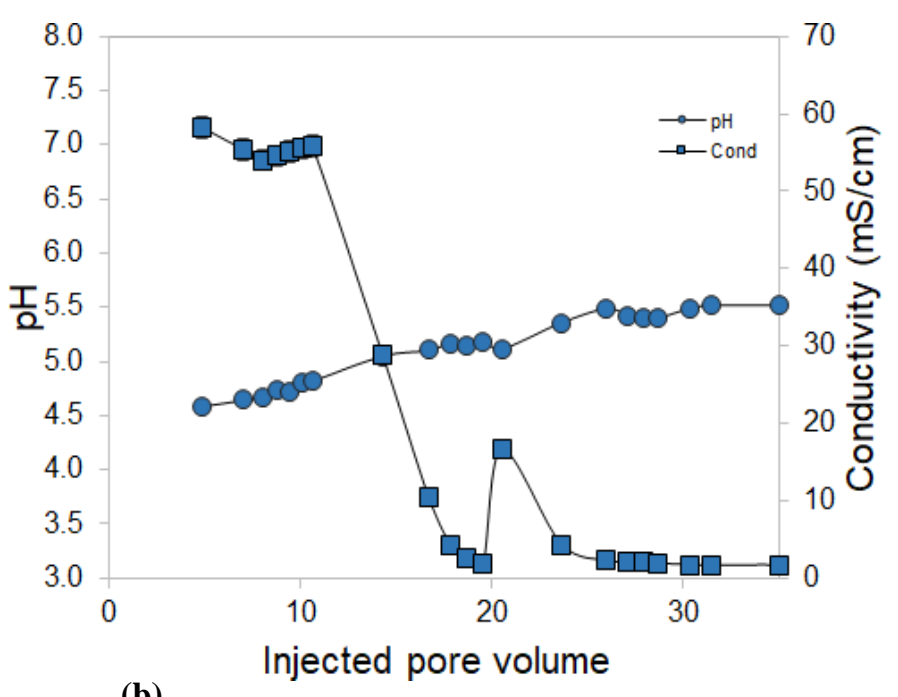

(b)

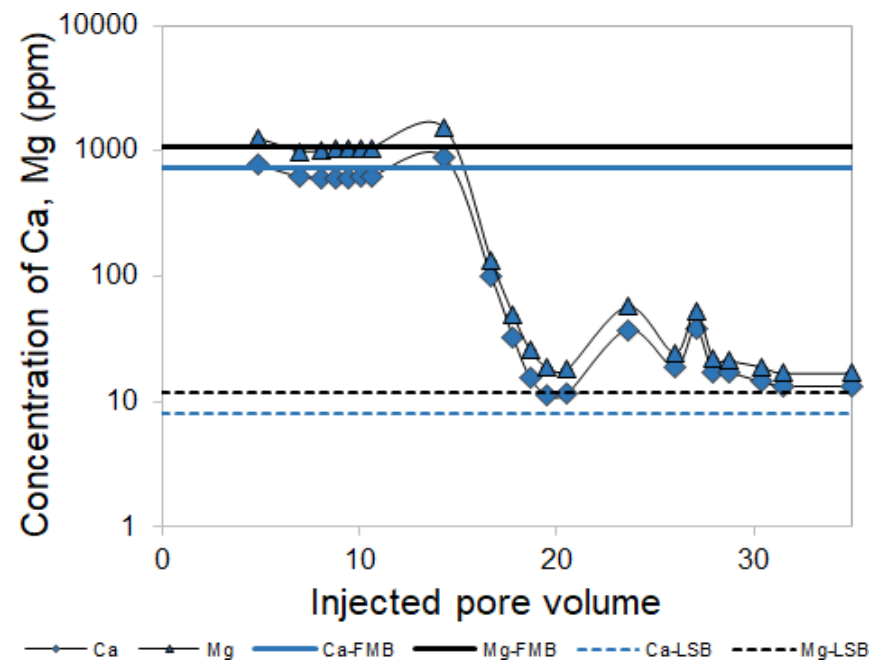

(c)

Figure 2: Flooding on core $\mathrm{S} 02$ at $50{ }^{\circ} \mathrm{C}$, (a) oil recovery (b) effluents' $\mathrm{pH}$ and conductivity (c) concentrations of $\mathrm{Ca}^{2+}$ and $\mathrm{Mg}^{2+}$ ions in effluents. The straight and dashed lines indicate $\mathrm{Ca}^{2+}$ (coloured) and $\mathrm{Mg}^{2+}$ (black) concentrations in connate water and injected brines respectively.

Figure 3 shows the results of the flooding process carried out at $70^{\circ} \mathrm{C}$. During the secondary high salinity FMB flooding, recovery of $79.12 \%$ OIIP was made with continuous injection of 6.29 PV brine until no oil production was observed. The implementation of the LSB flooding in the tertiary mode resulted in an additional recovery of $6.73 \%$ OIIP that increased oil production to $85.85 \%$ OIIP. Further flooding with LSEZ brine in post-tertiary mode resulted in an incremental recovery of $3.04 \%$ OIIP and total recovery of $88.89 \%$ OIIP. The $\mathrm{pH}$ analysis of effluents from this flooding (Figure $3 \mathrm{~b}$ ) shows progressive increment in $\mathrm{pH}$ with change in injection fluid from FMB to LSB and then to LSEZ brine. This is consistent with the earlier lower temperatures $\left(25{ }^{\circ} \mathrm{C}\right.$ and $\left.50{ }^{\circ} \mathrm{C}\right)$ floodings. Also, the conductivity measurements showed a similar trend to the previous floodings with initial high values that later reduced to relatively low values.
Finally, the results of the ions concentration analysis showed that variation in concentrations of $\mathrm{Ca}^{2+}$ and $\mathrm{Mg}^{2+}$ during this flooding have the same trend with the lower temperatures floodings. However, earlier production of low concentrations of $\mathrm{Ca}^{2+}$ and $\mathrm{Mg}^{2+}$ was observed during LSB flooding and the LSB breakthrough front observed from this flooding occurred at around $8 \mathrm{PV}$. This is much earlier than the $25^{\circ} \mathrm{C}$ and $50{ }^{\circ} \mathrm{C}$ floodings that occurred at $22 \mathrm{PV}$ and $14 \mathrm{PV}$ respectively. Furthermore, these concentrations were initially higher than the injected but later reduced to the injected concentration during LSB injection. The continuous flooding with LSEZ brine however resulted in further increase in the concentrations of these ions. This increase in ionic concentrations during LSEZ flooding was associated with a sudden bump in the concentration profile, which is consistent with the other floodings. The reason for this sudden bump is not very clear and it will require further study. 


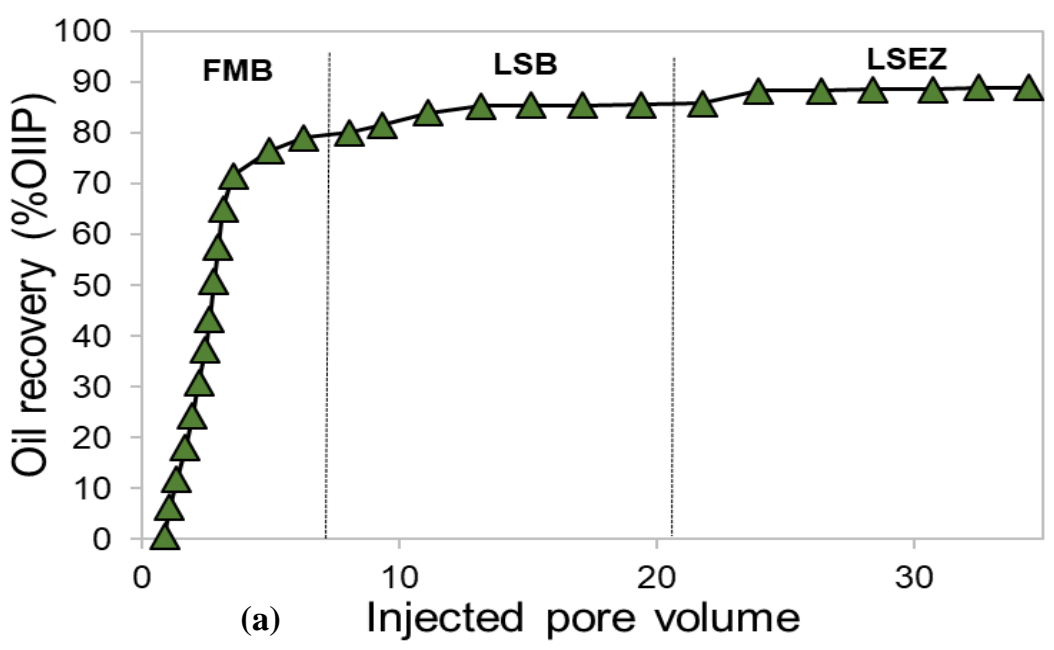

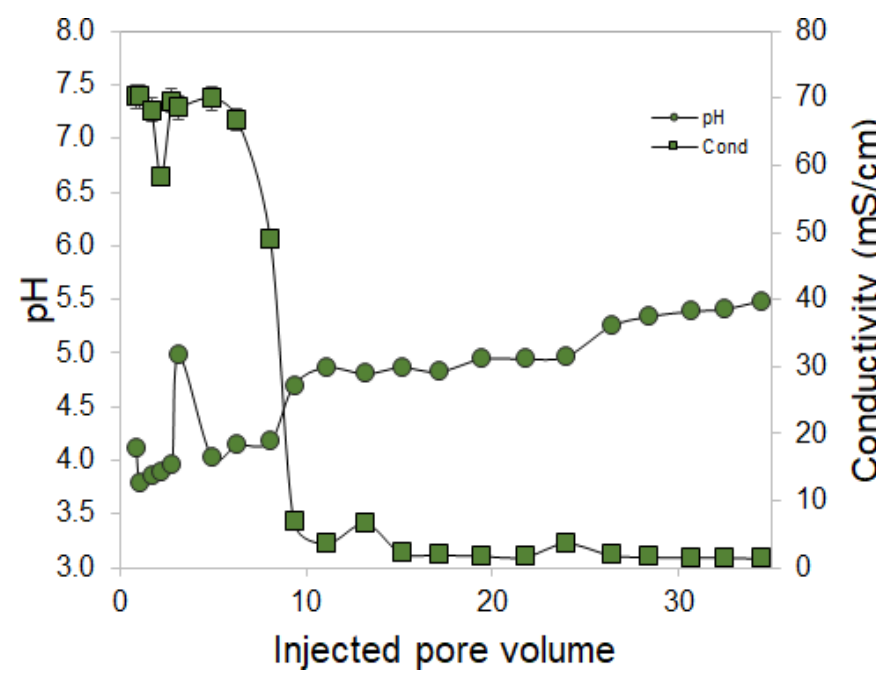

(b)

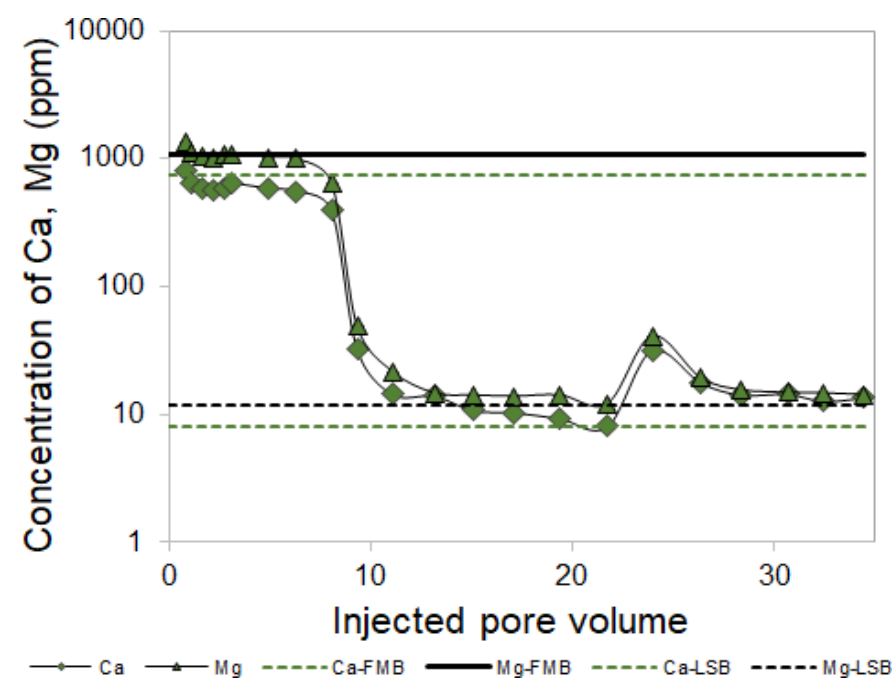

(c)

Figure 3: Flooding on core $\mathrm{S03}$ at $70{ }^{\circ} \mathrm{C}$, (a) oil recovery (b) effluents' $\mathrm{pH}$ and conductivity (c) concentrations of $\mathrm{Ca}^{2+}$ and $\mathrm{Mg}^{2+}$ ions in effluents. The straight and dashed lines indicate $\mathrm{Ca}^{2+}$ (coloured) and $\mathrm{Mg}^{2+}$ (black) concentrations in connate water and injected brines respectively.

\section{B. Discussion of Results}

From all the floodings carried out with secondary FMB injection, continuous oil production was observed until residual oil saturation was attained when no further oil production occurs. This process is synonymous to water flooding that is usually implemented in oil reservoir after primary recovery process (AlAdasani and Bai, 2010). During the low temperature flooding, oil production of $65.94 \%$ OIIP was achieved, which is comparable with results of previous studies such as Nasralla et al. (2011) and AlQuraishi, et al. (2015). Also, implementation of LSB and LSEZ in tertiary and post-tertiary modes respectively increased oil recovery beyond the secondary oil recovery at all investigated temperatures. Thereby, demonstrating the enhanced oil recovery potential of these modified injected brines. This is consistent with previous studies that observed increased oil with the use of LSB and enzyme application such as (Nasiri, 2009; Austad, RezaeiDoust, and Puntervol, 2010; Morrow and Buckley, 2011; Udoh and Vinogradov, 2019b and 2019c).
Comparing the recoveries made from all the flooding processes at different temperatures as illustrated in Figure 4a, it is obvious that oil recovery increased with increase in system temperatures. The highest recovery of recoveries of $79.12 \%$ OIIP, $85.85 \%$ OIIP and $88.89 \%$ OIIP were made with FMB, LSB and LSEZ brine flooding respectively during $70{ }^{\circ} \mathrm{C}$ flooding. These correspond to increased recovery of $0.57 \%$, $2.96 \%$ and $3.55 \%$ over the recoveries made from the three stages during $50{ }^{\circ} \mathrm{C}$ flooding while the corresponding increased recoveries made over the three stages during $25^{\circ} \mathrm{C}$ flooding are $14.18 \%, 11.19 \%$ and $8.89 \%$ respectively. This shows that oil recovery made during low temperature is significantly lower than high-temperature flooding but as the temperature increases, the difference in the recoveries became less significant. This shows the significance of carrying out enhanced oil recovery investigations at relevant reservoir temperature. Furthermore, the observed increase in oil production from all the flooding processes as the temperature increases can be related reduction 
in oil viscosity that enhances it mobility during flooding (Aadland, et al., 2019). The observed increase in the ionic concentrations of the effluents however suggests the possibility of combined mechanisms effect during LSB and LSEZ floodings.

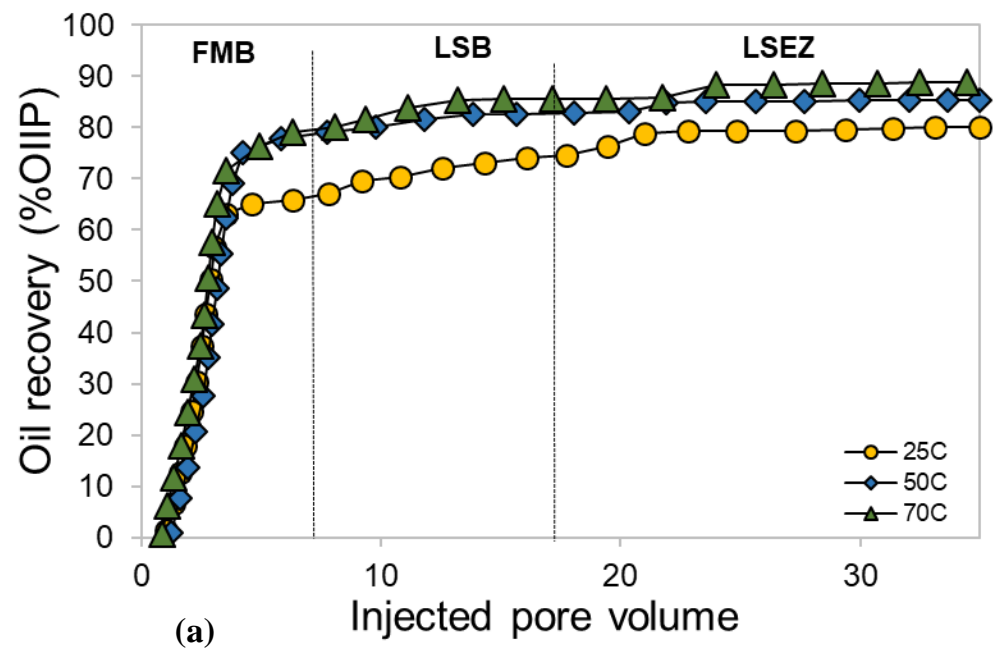

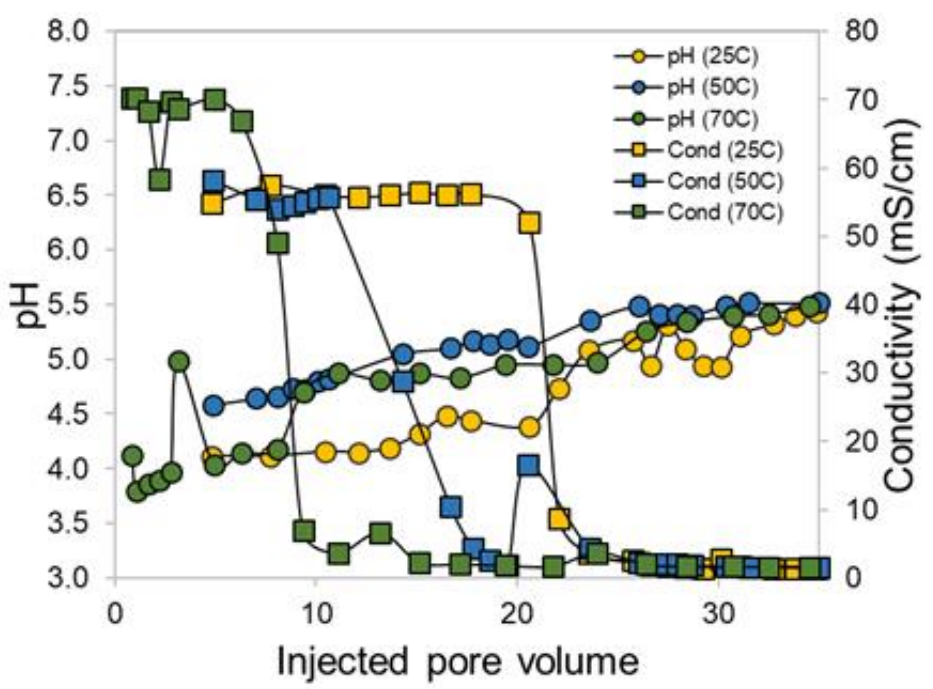

(b)

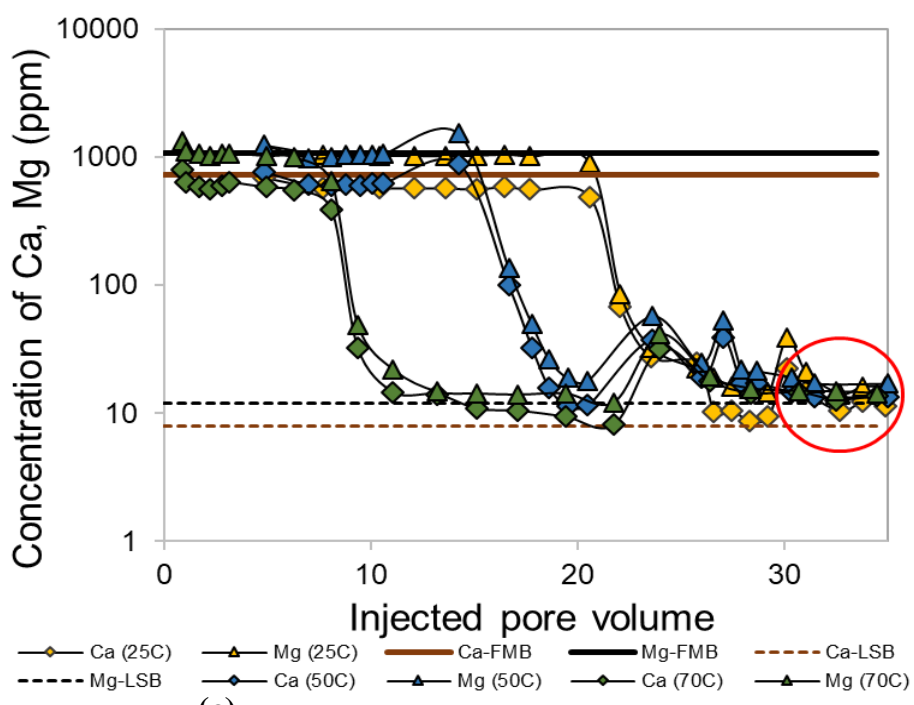

(c)

Figure 4: Comparison of all the flooding process carried at different temperatures: (a) oil recovery (b) effluents' pH and conductivity (c) concentrations of $\mathrm{Ca}^{2+}$ and $\mathrm{Mg}^{2+}$ ions in effluents. The straight and dashed lines indicate $\mathrm{Ca}^{2+}$ (coloured) and $\mathrm{Mg}^{2+}$ (black) concentrations in connate water and injected brines respectively.

Comparing the $\mathrm{pH}$ measurements of all the floodings as demonstrated in Figure 4b, a general progressive increase in $\mathrm{pH}$ was observed with change in injection brine from FMB to LSB and then LSEZ. Relating the results of this study to the proposed mechanisms for effective LSB flooding, it is evident that the observed increase in $\mathrm{pH}$ of all the floodings was not high enough for it to generate in-situ surfactant and IFT reduction as proposed by previous studies (Tang and Morrow, 1999; McGuire et al., 2005; Austad et al., 2010; Alagic and Skauge, 2010). Also, previous study by Udoh and Vinogradov (2019c) showed that the LSB brine used in this study did not generate any significant oil-brine IFT reduction. Hence, in-situ surfactant generation that may result in IFT reduction is not a mechanism underlying the effective LSB flooding observed in this study. The observed incremental recovery during posttertiary LSEZ flooding can however be related to IFT reduction because the result of the study by Udoh and Vinogradov (2019c) showed that the greenzyme used in this study has IFT reduction capacity. Also from Figure $4 b$, it is evident that the $\mathrm{pH}$ analyses did not show any significant effect of temperature on rock-fluid interactions during these floodings neither can a clear correlation be established between the recovery and $\mathrm{pH}$ measurements.

However, the conductivity analyses of these floodings showed a distinct trend with change in temperature. The highest temperature $\left(70^{\circ} \mathrm{C}\right)$ flooding was characterised by the earliest front of the LSB breakthrough which was preceded with initial very high conductivity. Also, the medium temperature $\left(50{ }^{\circ} \mathrm{C}\right)$ flooding was associated with earlier front of the LSB breakthrough while the low temperature $\left(25^{\circ} \mathrm{C}\right)$ flooding shows late breakthrough front. This trend was also seen with the ionic concentrations analyses of these floodings as evidently shown in Figure 4c. Since the results of the ionic concentration analyses gave a distinct concentration of the divalent cations in the effluent while the conductivity only 
gave the overall ionic activity, the former was used for the interpretation of the results. From all the floodings, initial high concentrations of $\mathrm{Ca}^{2+}$ and $\mathrm{Mg}^{2+}$ which were equivalent to their respective concentrations in connate water saturation and injected FMB was observed.

These concentrations later reduced to slightly above the injected concentrations during LSB and LSEZ floodings but their respective breakthrough time varied with the system temperature. The earlier breakthrough observed with higher temperatures $\left(50\right.$ and $70{ }^{\circ} \mathrm{C}$ ) floodings can be associated with kinetic effect that promotes fast mixing of the injected brine with the high salinity brine in the core pores, thereby resulting in early LSB breakthrough in those floodings.

Furthermore, continuous flooding of each core with LSB and LSEZ brines resulted in the same range of $\mathrm{Ca}^{2+}$ and $\mathrm{Mg}^{2+}$ concentrations that is slightly above the injected concentrations for all the floodings irrespective of the system temperature. This suggests the possibility of ionic interactions between these brines and rock surfaces that resulted in the desorption $\mathrm{Ca}^{2+}$ and $\mathrm{Mg}^{2+}$ from the rock surface and hence, increasing their concentration in effluents. This can be related to multi-component ion exchange (MIE) mechanism proposed by (Lager et al., 2008) and electric double-layer (EDL) expansion mechanism proposed by Ligthelm, et al., 2009.

The MIE takes place when the polar components of oil are removed from the rock surface and then replaced by divalent cation. This will invariably result in reduction of divalent cations concentrations in the effluent but on the contrary, slight increase in these concentrations were observed in this study. The double-layer expansion mechanism is however related to concentration in the diffusion layer. During the high salinity flooding, the EDL is characterised by compacted counter-ions and reduced thickness due to abundant presence of divalent cations in the solution. However, with the introduction of lower ionic strength electrolyte such as LSB and LSEZ, a diffusion gradient is induced in the EDL between the compacted counter-ions and the bulk electrolyte solution thereby resulting in the expansion of the EDL.

This therefore leads to increased repulsive force between adsorbed polar group of oil the rock surface, which invariably released the oil molecules and alters the rock surface toward increased water-wetness. Also, the observed effect of LSEZ brine in this process can be associated with the surface activity property of greenzyme and its wettability alteration potential as demonstrated by previous studies carried out by Udoh and Vinogradov (2019a; 2019c). Other studies also showed that greenzyme has a strong affinity for the sandstone rock surface (Udoh, 2019; Udoh and Ekanem, 2020).

It is evident from this study that the use of LSB and LSEZ injection in tertiary and post-tertiary respectively enhanced oil production irrespective of the system temperature. Relating the results of this study to the previous studies and the proposed mechanisms for low salinity enhanced oil recovery, combined effects of electric double-layer expansion and oil viscosity reduction are attributable to the observed incremental recovery during LSB floodings. The additional recovery observed during LSEZ flooding can however be attributed to combined effects of electric double-layer expansion, oil viscosity and interfacial tension reductions.

\section{CONCLUSION}

In this study, experimental investigations on effect of temperature on enhanced oil recovery processes of low salinity brine (LSB) and combined low salinity enzyme (LSEZ) brine flooding in sandstone rock cores were carried out. The results showed that implementation of LSB and LSEZ floodings in tertiary and post-tertiary increased oil recovery beyond the secondary high salinity flooding. This observed increased oil recovery during LSB and LSEZ floodings was associated with progressive slight increase in $\mathrm{pH}$ and increase in divalent cations in the effluents.

Also, increase in system temperatures was associated with increased oil recovery but no significant difference relative to temperature changes was observed in all the effluents analyses of the FMB flooding. Hence, the observed increased oil recovery with increase in system temperature during FMB flooding is attributable to reduction in oil viscosity. The observed increase in oil recovery during LSB and LSEZ floodings is attributable to combined effects of electric doublelayer expansion and oil viscosity reduction but IFT reduction also enhanced LSEZ EOR process.

Acknowledgements: The author appreciates Biotech Processing Supply, Dallas Texas for the supply of greenzyme used in this study. The assistance of Dr. Akanji, Dr. Vinogradov and Dr. Kindness of the University of Aberdeen is highly appreciated.

\section{REFERENCES}

Aadland, R. C.; T. D. Jakobsen; E. B. Heggset; H. LongSanouiller; S. Simon; K. G. Paso; K. Syverud and $O$. Torsæter. (2019). High-temperature core flood investigation of nanocellulose as a green additive for enhanced oil recovery. Nanomaterials, 9(5), p. 665.

Al-Adasani, A. and Bai, B. (2010). Recent Developments and Updated Screening Criteria of Enhanced Oil Recovery Techniques. SPE-130726-MS.

Alagic, E. and Skauge, A. (2010). Combined low salinity brine injection and surfactant flooding in mixed-wet sandstone cores. Energy and Fuels, 24(6), 3551-3559.

AlQuraishi, A.; S. AlHussinan and H. AlYami (2015). Efficiency and recovery mechanisms of low salinity water flooding in sandstone and carbonate reservoirs. In Offshore Mediterranean Conference and Exhibition, Offshore Mediterranean Conference.

Austad, T.; A. RezaeiDoust and T. Puntervol (2010). Chemical Mechanism of Low Salinity Water Flooding in Sandstone Reservoirs. J2: SPE-129767-MS.

Hughes, D.; S. Larsen and R. Wright (2010). Review of Low Salinity Water Flooding. Report for Department of Energy and Climate Change, 12. 
Johannessen, A. M. and Spildo, K. (2013). Enhanced oil recovery (EOR) by combining surfactant with low salinity injection. Energy and Fuels, 27(10), 5738-5749.

Johannessen, A. M. and Spildo, K. (2014). Can lowering the injection brine salinity further increase oil recovery by surfactant injection under otherwise similar conditions? Energy and Fuels, 28(11), 6723-6734.

Khusainova, A.; A. A. Shapiro; E. H. Stenby and J. M. Woodley (2013). Wettability Improvement with Enzymes: Application to Enhanced Oil Recovery under Conditions of the North Sea Reservoirs. Graduate Schools Yearbook 2012.

Kuznetsov, S. I. (2012). The microflora of lakes and its geochemical activity. University of Texas Press.

Lager, A. (2008). Low salinity oil recovery - An experimental investigation. Petrophysics, 49(1), p. 28-35

Levitt, D. B. (2006). Experimental evaluation of high performance EOR surfactants for a dolomite oil reservoir.

Ligthelm, D.; J. Gronsveld; J. Hofman; N. Brussee; F. Marcelis and H. V. Linde (2009). Novel waterflooding strategy by manipulation of injection brine composition. Paper presented at 71st European Association of Geoscientists and Engineers Conference and Exhibition 2009: Balancing Global Resources. Incorporating SPE EUROPEC 2009.

McGuire, P. L.; J. R. Chatham; F. K. Paskvan; D. M. Sommer and F. H. Carini (2005). Low salinity oil recovery: An exciting new EOR opportunity for Alaska's north slope. Paper presented at SPE western regional meeting, Irvine, California. Society of Petroleum Engineers.

Morrow, N. and Buckley, J. S. (2011). Improved oil recovery by low-salinity waterflooding. Journal of Petroleum Technology, 63(5), 106-112.

Nasiri, H.; K. Spildo and A. Skauge (2009). Use of enzymes to improve waterflood performance. Paper presented at International Symposium of the Society of Core Analysts, Noordwijk, Netherlands, p. 27-30.

Nasralla, R. A.; M. B. Alotaibi and H. A. Nasr-El-Din (2011). Efficiency of Oil Recovery by Low Salinity Water Flooding in Sandstone Reservoirs. Paper presented at SPE Western North American Region Meeting, 7-11 May, Anchorage, Alaska, USA, SPE.

Pu, H.; X. Xie; P. Yin and N. R. Morrow (2008). Application of coalbed methane water to oil recovery by low salinity waterflooding. Paper SPE 113410 presented at the SPE. In DOE Symposium on Improved Oil Recovery, Tulsa, Oklahoma, pp. 20-23.

RezaeiDoust, A.; T. Puntervold; S. Strand and T. Austad. (2009). Smart water as wettability modifier in carbonate and sandstone: A discussion of similarities/differences in the chemical mechanisms. Energy and fuels, 23(9), 4479-4485.

Sharma, M. M. and Filoco, P. R. (2000). Effect of brine salinity and crude-oil properties on oil recovery and residual saturations. SPE Journal, 293-300.

Sheng, J. J. (2014). Critical review of low-salinity waterflooding. Journal of Petroleum Science and Engineering, 120, 216-224.

Sohrabi, M.; P. Mahzari; S. A. Farzaneh; J. R. Mills; P. Tsolis and S. Ireland (2015). Novel insights into mechanisms of oil recovery by low salinity water injection. Paper SPE172778 presented at the SPE Middle East Oil \& Gas Show and Conference, Manama, Bahrain, 8-11 March. DOI: http://dx. doi. org/10.2118/172778-MS.

Tang, G. Q. and Morrow, N. R. (1997). Salinity, temperature, oil composition, and oil recovery by waterflooding. SPE Reservoir Engineering, 12(4), 269-276.

Tang, G. Q. and Morrow, N. R. (1999). Influence of brine composition and fines migration on crude oil/brine/rock interactions and oil recovery. Journal of Petroleum Science and Engineering, 24(2-4), 99-111.

Udoh, T. (2019). Comparative Study on Adsorption of Biologically Generated Surface Active Agents on Carbonate and Sandstone Rock Surface. International Journal of Current Research and Academic Review, 7(2), 21-36.

Udoh, T. H. and Ekanem, V. (2020). Experimental Investigation of Greenzyme Adsorption on Sand Surface. ABUAD Journal of Engineering Research and Development, 3(1), 83-89.

Udoh, T. and Vinogradov, J. (2019a). Experimental Investigations of Behaviour of Biosurfactants in Brine Solutions Relevant to Hydrocarbon Reservoirs. Colloids and Interfaces, 3(1), 24.

Udoh, T. and Vinogradov, J. (2019b). Effects of Temperature on Crude-Oil-Rock-Brine Interactions During Controlled Salinity Biosurfactant Flooding. Paper SPE 198761 presented in SPE Nigeria Annual International Conference and Exhibition, Lagos, Nigeria. Society of Petroleum Engineers. doi:10.2118/198761-MS

Udoh, T. and Vinogradov, J. (2019c). A Synergy between Controlled Salinity Brine and Biosurfactant Flooding for Improved Oil Recovery: An Experimental Investigation Based on Zeta Potential and Interfacial Tension Measurements. International Journal of Geophysics, 2019, 15.

Udoh, T.; L. Akanji and J. Vinogradov (2018). Experimental Investigation of Potential of Combined Controlled Salinity and Bio-Surfactant CSBS in Enhanced Oil Recovery EOR Processes. Paper SPE 193388 in SPE Nigeria Annual International Conference and Exhibition. Society of Petroleum Engineers. doi:10.2118/193388-MS

Van Hamme, J. D.; A. Singh and O. P. Ward (2006). Physiological aspects: Part 1 in a series of papers devoted to surfactants in microbiology and biotechnology. Biotechnology Advances, 24(6), 604-620.

Wang, W. (2010). Experimental Study of Oil Displacement by the Bio-enzyme at the Third Type Reservoirs of Sabei Blocks. Power and Energy Engineering Conference (APPEEC), Asia-Pacific. 1-4

Wang, Y.; A. Kantzas; B. Li; Z. Li; Q. Wang and M. Zhao (2008). New Agent for Formation-Damage Mitigation in Heavy-Oil Reservoir: Mechanism and Applicatio. SPE International Symposium and Exhibition on Formation Damage Control.

Xia, J. (2001). Protein-Based Surfactants: Synthesis: Physicochemical Properties, and Applications (101 ed.). Marcel Dekker, Inc. 270 Madison Avenue, New York, NY 10016. 